\title{
Impact of digital marketing and current scenario in India
}

\author{
Rakesh Pandit $^{1^{*}}$, Anshu Chauhan ${ }^{2}$ \\ ${ }^{1,2}$ Research Scholar, ${ }^{1}$ Institute of Management Technology, Ghaziabad, Uttar Pradesh, ${ }^{2}$ Innovative Education and Scientific Research \\ Foundation (IESRF), New Delhi, India
}

*Corresponding Author: Rakesh Pandit

Email: rakesh.its@gmail.com

\begin{abstract}
India is fastest growing large economy in the world, it still popularly known as the country of villages. Digital marketing industry in India is a booming career today. In a country with a rapid growth economy, it is expected to have a very high significant growth in Digital marketing career. The growth in the digital marketing trends is making a very substantial impact on marketing and advertisement. Digital Marketing industry in India is spread to almost all the business sectors. Some of the applications of E-Marketing are shopping and order tracking, online banking, payment systems and content management.

The power of digital marketing allows geophysical barriers to disappear making all consumers and businesses on earth potential customers and suppliers. It is known for its ability to allow business to communicate and form a transaction anywhere and anytime.
\end{abstract}

Keywords: Digital marketing, Technology and rural marketing, E-marketing.

\section{Introduction}

Indian market for the consumer products is made up of two distinct parts, one is urban and other is rural market. Rural Marketing is the way toward taking specific goods and services to the provincial market prompting trades among urban and rustic markets at the same time fulfilling consumer need and accomplishing organisational goals. Around 70\% Indians are still staying in 6.5 lakhs villages with $50 \%$ of nation's population heavily dependent on agriculture. ${ }^{1}$ With improvement in infrastructure, villages came closer to cities. Mobile and, to some extent, internet brought villages closer to urban population further and hence, rural India became familiar to urban lifestyle. This motivated rural people to increase prosperity and improve their lifestyle. A number of telecom players have been trying to get grip on the rural market in a variety of ways. There is no doubt that rural market reveals opportunities and great attraction to service providers. But, it not as easy as it seems on surface. This rural marketing poses a variety of challenges, and, therefore, the service providers has to work hard to tackle these challenges tactfully. The main aim of the study to observe the potentiality of digital marketing effect on rural people and find various problems that are being faced by rural people. ${ }^{2}$

\section{Digital Marketing}

Digital marketing is the use of the internet, mobile devices, social media, search engines, display advertising and other channels to reach consumers. As a subset of traditional marketing, digital marketing goes beyond the internet to include Short Message Service (SMS), Simple Notification Service (SNS), search engine optimization (SEO), electronic or interactive billboards and other online ads (such as banner ads) to promote products and services.

\section{Review of Literature}

The digital marketing in India report by the International Journal of Advanced Research Foundation revealed that summarized that India is getting to see the golden period of the Internet sector between 2013 to 2018 with incredible growth opportunities and secular growth adoption for ECommerce, Internet Advertising, Social Media, Search, Online Content, and Services relating digital marketing. ${ }^{3}$

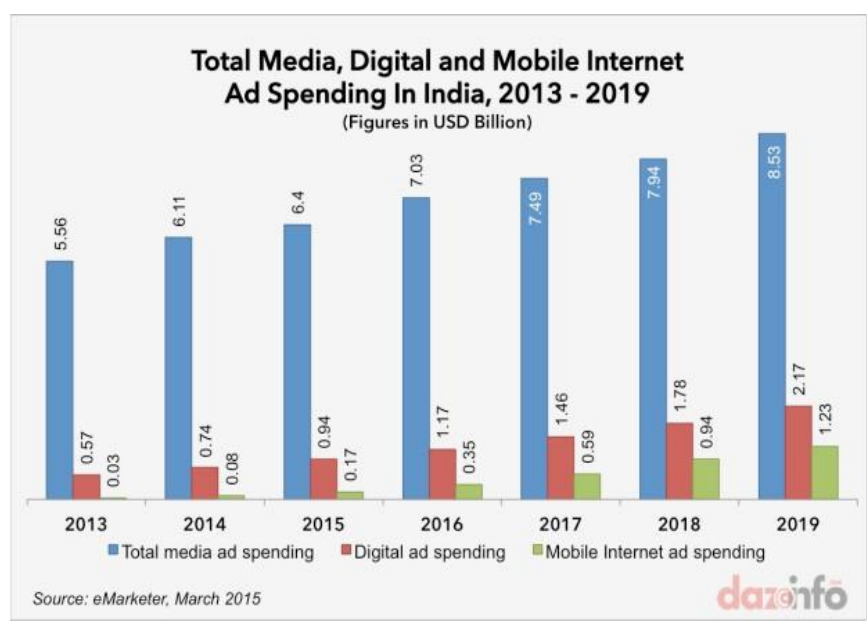

Fig. 1

Total media, digital and mobile internet ad spending in India (2013-2019)

Saroj Kumar Verma (2013) examined the challenges and opportunities of rural marketing in India. One of the major 
challenges identified in the study were the non-homogenous and scattered nature of the market. Other challenges included seasonal marketing, low per capita income, transportation, and warehousing on the other hand, a huge population seen as huge consumer base in rural segment is admired as an opportunity for the marketers to channelize their efforts. Increase in purchasing power, as reported by Rural Marketing Association of India (RMAI) is another conclusion of the study which highlights that there indeed exists an untapped market in this segment. ${ }^{4}$

\section{Objective of the Study}

To observe the potentiality of digital marketing effect on rural people and find various problems that are being faced by rural people. The study is to explore the results of digitization and impact of revolution on progress of private and public sectors with expert professionals in improvement of revolutionary target and make India Power County in globe.

\section{Methodology}

This study methodology is descriptive in digital market by nature. Secondary data collection technique was implemented. The informative data is used in this study has been collected from various sources, different websites and published research papers.

\section{Digital technology for HR professionals}

The recruitment process varies from organization to organization and institute to institute and depend on the mission and vision of the organization/institute. The Society for Human Resource Management (SHRM) a largest HR professional society developed customized talent acquisition and benchmarking guide for talent acquisition, hiring and recruitment. This process can be used for all industry of all sizes of staff (SHRM, 2017). The Linked in Talent Solutions proposed a 12 metrics to measure recruitment impact for small and medium sized business houses (Recruitment Metrics Cheat Sheet, 2012). A new and proactive approach using metrics to build an effective hiring process, what to measure, how to measure and communicate results to senior management was develop by David Earle (2012). Dutta et al. (2015) critically reviewed and presented the results of his case study on improving the quality of hire through focused metrics. Davenport et al. (2010) emphasized the idea of competing of talent analytics and recruitment and its application in their review. The quality of hire was measured using the study that measured performance appraisal system using multinomial logistic regression analysis for agricultural research sector employees. ${ }^{5}$

\section{Cost reduction}

Digital advertising enables the advertisers to spare money. It costs relatively low than the purported conventional advertising stations like TV, papers, radio, flags, magazine and so on. A few sites and business profiles create gigantic traffic for completely free. It is an incredible choice for advertisers to spread their business all through the world with no significant expense.

\section{Accessibility}

The World Wide Web never rests for whenever. So, the ad will labour for 24 hours. Utilizing the electronic business, your commercial will physically display for 24 hours every day and 7 days per week and 365 days in a year. Promotion will consistently be before your focused-on clients. This is one of the fundamental significant highlights of computerized advertising that we can't maintain a strategic distance from while discussing focal points and impediments of advanced showcasing.

\section{Purchaser's convenience to shop online}

Online shopping is a developing pattern. For the prevalence and abilities of computerized advertising, clients are increasingly intrigued by web-based shopping. A client can purchase a thing whether it is in his/her nation or in abroad. Today separation is certainly not an issue to a client. Additionally, a client can get the chance of picking his/her material from such huge numbers of alternatives. A huge bit of individuals currently enjoys internet looking for its such a significant number of advantages. In this way, advanced showcasing opens up another open door for both the organization and the client. Presently a retailer and a client can associate with one another effectively.

\section{Worldwide advertisement}

This is one of the most significant highlights of advanced promoting. It empowers the organizations to promote worldwide and there is no hindrance, having such a significant number of land contrasts. Thus, an organization can undoubtedly grow its business with no additional exertion. Sitting in a remote spot, an organization can spread its business all through the world. This will lead the organization to flaunt it highlights to the remainder of the world. This worldwide ad will spread your company's notoriety around the world.

\section{Some of genuine problems associated with rural market include}

\section{Digital illiteracy}

As per the Pattern of Consumer Expenditure Report 2011, only 3.5 households in 1000 rural households in rural India 
had internet connectivity at home in 2009-2010. And there are close to 90,000 rural info kiosks (Common Service Centres, Community Information Resource Centres and others) in India, and around 5452 CSCs are located in the state. However, these kiosks lack internet connectivity and services to delivery at people's doorsteps. To make India digitally literate, it is important 3.5 million people to be digitally literate. ${ }^{6}$

\section{Wide and scattered market}

Wide and scattered market is difficult to reach in both the aspects - promotion and distribution. Rural India is spread in the entire county in around 6 lakhs villages of different sizes while urban population is concentrated in around 3200 cities. Most of villages are extremely small with population less than 500 people. Only one percent (6300) villages have a population of more than 5000. It is challenging tasks to choose target markets and to serve them effectively.

\section{Language problem}

Language is a main constrains in communication strategies. Multiplicity of languages spoken in rural areas makes marketing activities difficult. Languages differ from state to state, and area to area in the same state. While designing advertising, personal selling, and publicity strategies, marketers cannot fulfill linguistic expectation of all rural people. Promotion programme always lacks versatility.

\section{Urban marketers $v /$ s rural customers}

The executives in companies cannot understand the consumer psychology of rural markets. Lack of awareness and understanding about consumer behaviour in rural markets create problems in formulating marketing strategies. Rural and urban customers significantly differ in terms of habits, tastes, uses, preferences, and other such aspects. So, any attempt to satisfy rural customers with urban mind (marketing executives born and brought-up in urban climate) results into vain endeavor.

\section{Conclusion}

Digital marketing in rural area is very immaculate zone and has lot of undiscovered potential but the techniques are yet being devised to explore this area. In long term, digital will help to increase the consumption in rural India and will also create employment opportunities, thereby increasing disposable income- this in turn will have positive effect on economic growth of the country. Present study reveals such opportunities for the marketers to grab untapped potentiality in rural market.

\section{Source of Funding}

None.

\section{Conflict of Interest}

Not declare.

\section{Acknowledgments \\ None}

\section{References}

1. https://www.digitalvidya.com/blog/growth-of-digitalmarketing-industry-in-india/.

2. Shireesh Diveeker. (2017), Digital Marketing for Rural India: intelliassist new-age business solutions Retrieved from http:// http://intelliassist.co.in/digital marketing-rural-india.

3. https://www.digitalvidya.com/blog/growth-of-digitalmarketing-industry-in-india

4. Verma SK. Rural marketing in India. Anusandhanika. 2013;5(1):16-22.

5. Prasad KDV, Mrutyunjaya R, Vaidya R. Recruitment metrics and accomplishments: A study with reference to information technology sector. J Manag Res Anal. 2019;6(2):106-11.

6. https://defindia.org/national-digital-literacy-mission.

How to cite: Pandit R, Chauhan A. Impact of digital marketing and current scenario in India. J Manag Res Anal. 2020;7(1):3-5. 